\title{
Serum Vitamin D and Immunoglobulin E Levels In Patients With Seasonal Allergic Conjunctivitis
}

\author{
Khashim Alswailmi $F^{a}$, Ali Shah $\mathrm{SI}^{\mathrm{a}}$, Al-Mazaideh $\mathbf{G M}^{\mathrm{a}}$, Sikandar $\mathbf{M Z}^{\mathrm{b}}$ \\ ${ }^{a}$ University of Hafr Al-Batin, Hafar Al Batin, Saudi Arabia. \\ ${ }^{b}$ Central Park Medical College, Lahore, Pakistan.
}

\author{
Keywords \\ Allergy, Vitamin D, Immunoglobulin E, Ocular \\ allergy, Seasonal allergic conjunctivitis \\ Corresponding Author \\ Dr. Syed Imran Ali Shah \\ Professor of Biochemistry, \\ University of Hafr Al-Batin, Hafar Al-Batin, \\ Sauid Arabia \\ Tel: +966534510690 \\ e-mail: simranali@uhb.edu.sa \\ Received: 4 January 2021 ; Accepted: 7 April \\ 2021 \\ Doi: https://doi.org/10.31436/imjm.v20i3
}

\section{ABSTRACT}

INTRODUCTION: Seasonal allergic conjunctivitis (SAC) is a mild but common immunoglobulin $\mathrm{E}$ ( $\mathrm{IgE}$ ) mediated ocular allergy. Low serum vitamin D levels have been related to some allergic disorders but such data in the clinical context of SAC are missing. Our study investigated serum $\operatorname{IgE}$ and vitamin D levels in SAC patients. MATERIALS AND METHODS: A cross-sectional case-control study was conducted at University of Hafr Al-Batin, Saudi Arabia involving patients with established diagnosis of SAC and agematched healthy control subjects. Standard patient evaluation of eye dryness (SPEED) questionnaire was scored for the frequency and severity of symptoms. Blood samples were taken to quantify serum $\operatorname{IgE}$ and vitamin D levels. Mean +- SD were calculated and independent sample t-test was applied for comparison between groups. RESULT: A total of 52 subjects were recruited into the study in which 26 subjects were patients aged between 20-60 years with an established diagnosis of SAC and another 26 subjects were age-matched healthy controls without any allergy. Mean serum IgE, vitamin D level and SPEED scores were significantly higher in SAC patients than in healthy control (2181.09 $\mathrm{IU} / \mathrm{ml}+-1062.33$ vs $54.83 \mathrm{IU} / \mathrm{ml}+-26.67 ; 38.96 \mathrm{ng} / \mathrm{ml}+-11.37$ vs. $29.47 \mathrm{ng} / \mathrm{ml}+$ $11.73 ; 19.42+-4.81$ vs. $2.19+-1.49)$ with p-value $0.001,0.005$, and 0.001 respectively. Mean vitamin D levels in both groups were within normal range. CONCLUSION: Higher serum vitamin D levels may be linked with SAC, but further research is needed to eliminate irregularities in the existing evidence on the influence of vitamin D in SAC.

\section{INTRODUCTION}

Ocular allergies are globally on the rise and constitute an increasing proportion of allergic disorders that have an adverse influence on health and economic productivity the world over. ${ }^{1}$ Conjunctival vulnerability to allergen exposure makes allergic conjunctivitis a common allergic disorder. Allergic conjunctivitis is typically characterized by inflammation of the conjunctiva leading to itching (pruritus), pink eye (hyperaemia), gritty sensation, conjunctival swelling (chemosis), visual blurring and watery eyes. ${ }^{2}$

Regions with high temperatures and humid climate have a high prevalence of allergic conjunctivitis. Severe allergic conjunctivitis, including vernal keratoconjunctivitis (VKC) and atopic keratoconjunctivitis (AKC) accompanied by visual loss through damage to ocular and corneal surfaces, is common in many South Asian countries. Mild forms of allergic conjunctivitis including seasonal allergic conjunctivitis (SAC) and perennial allergic conjunctivitis (PAC) account for nearly one-fifth of the worldwide burden of ocular allergies. ${ }^{3}$

Seasonal fluctuations, air and water pollution, chemical exposure, pollen, agricultural factors, genetic predisposition and co-morbidities such as diabetes mellitus have been linked to the development and progression of allergic conjunctivitis. $4,5 \mathrm{SAC}$ is an acute and short-term ocular allergy and its seasonality or cyclic nature is due to airborne allergens released by various plants on a seasonal basis. SAC is exclusively caused by type I allergic reaction mediated by immunoglobulin $\mathrm{E}(\mathrm{IgE}){ }^{4}$ In type 1 allergic reactions, exposure of sensitized individuals to allergens causes B- 
cell stimulation and $\operatorname{IgE}$ production. IgE triggers mast cell degranulation and release of allergic and inflammatory mediators including histamine, cytokines, leukotrienes and prostaglandins.., 7

The fat-soluble secosteroid vitamin D (cholecalciferol) is primarily produced by the skin cells on exposure to sunlight and also obtained through various animal and plant-based food sources. Cholecalciferol undergoes hydroxylation in the liver and kidney to yield its active form calcitriol. ${ }^{8}$ Vitamin $\mathrm{D}$ has been recently highlighted as a regulator of immunity and allergy through multiple mechanisms including suppression of interleukin and immunoglobulin production by $\mathrm{T}$ and $\mathrm{B}$ -cells respectively.9-11 However, the clinical evidence on the role of vitamin $\mathrm{D}$ in allergic disorders is inconclusive and such data on allergic conjunctivitis are particularly elusive. ${ }^{12}$

Although vitamin D deficiency has been linked with many ophthalmologic disorders including diabetic retinopathy, glaucoma, uveitis, myopia and age-related macular degeneration, data on its role in allergic conjunctivitis are scarce. ${ }^{13}$ The present study assessed serum vitamin $\mathrm{D}$ levels in patients with SAC along with serum $\operatorname{IgE}$ and complete blood count (CBC) testing and made comparisons with healthy individuals.

\section{MATERIALS AND METHODS}

We conducted a cross-sectional, case-control study at University of Hafr Al-Batin, Saudi Arabia in complete accordance with the ethical practice guidelines of the Declaration of Helsinki. Fifty-two adult subjects between the ages of 20 to 60 years were recruited for this study from the local population of Lahore, Pakistan after obtaining written informed consent. The participants were divided into 2 groups. Group 1 participants were subjects with established diagnosis of SAC $(n=26)$ and group 2 were age-matched healthy control subjects without any known history of allergy $(n=26)$. Subjects with any other active ocular pathology or past history of blepharitis, xeropthalmia, eye surgery and wearers of contact lenses were excluded from the study. Subjects using multivitamin supplements or steroidal medications up to three months before the time of enrolment were also excluded and so were those with known history of systemic illnesses including autoimmune, liver, kidney and/or bone diseases.

Demographic information and medical history were recorded for all the study participants. $5 \mathrm{ml}$ blood was obtained in lavender-cap plastic tubes containing ethylenediamine tetra-acetic acid (EDTA) for CBC test. Another $5 \mathrm{ml}$ blood was obtained in red-cap plastic tubes (BD Vacutainer ${ }^{\circledR}$ ) and centrifuged at 3000 revolutions/minute for 10 minutes. Separated serum was aliquoted and stored at $-20^{\circ} \mathrm{C}$ till further laboratory analysis. Serum vitamin D (25-hydroxy cholecalciferol) was measured using Elecsys ${ }^{\circledR}$ total vitamin D electrochemiluminescence binding assay (Roche Diagnostics, Switzerland) on Cobas ${ }^{\circledR}$ e411 analyser. The serum vitamin $\mathrm{D}$ assay had a functional sensitivity of $5 \mathrm{ng} / \mathrm{ml}$ with a measuring range of $3-70 \mathrm{ng} / \mathrm{ml}$. Serum $\operatorname{IgE}$ levels were quantified using Elecsys ${ }^{\circledR} \operatorname{IgE}$ double sandwich immunoassay double sandwich immunoassay (Roche Diagnostics, Switzerland) on Elecsys ${ }^{\circledR}$ immunoassay analyser. The functional sensitivity of serum $\mathrm{IgE}$ assay was $0.5 \mathrm{IU} / \mathrm{ml}$ with a measuring range of $0.1-2500 \mathrm{IU} / \mathrm{ml}$.

All participants were asked to fill the 8-item validated standard patient evaluation of eye dryness (SPEED) questionnaire. ${ }^{14}$ The SPEED questionnaire was used to assess the frequency and severity of ocular symptoms including dryness, grittiness or scratchiness, soreness or irritation, burning or watering and eye fatigue. Additionally, the questionnaire also considered patients' tolerability of ocular symptoms and their progression over the last three months. The score range of the questionnaire was from 0-28 with higher scores indicating increased intensity of ocular symptomatology. Datasheets with anonymized data were prepared in Microsoft Excel 2013 (Microsoft Corporation, USA) and imported for analysis using Statistical Package for Social Sciences (SPSS), version 23. Descriptive data were presented as frequencies and percentages. Group mean difference were assessed using independent sample t-test.

\section{RESULTS}

Out of the 26 subjects in each group, group 1 (patients with SAC) had 21 males and 5 females while group 2 
(healthy controls) had 17 males and 9 females. In group 1 , the mean age was $42.00+-16.03$ while in group 2 , the mean age was $45.50+-14.48$, with no difference between the groups $(\mathrm{p}=0.413)$. In group $2, \mathrm{SAC}$ alone was seen in $9(35 \%)$ patients, SAC with allergic rhinitis was seen in 12 patients $(46 \%)$ and SAC with other extraocular allergies was seen in $5(19 \%)$ patients.

Ocular symptoms were much more common in group 1 as compared to group 2 (Table I). Hyperaemia was seen in $80.76 \%$ of the group 1 subjects followed by pruritis $(69.23 \%)$ and watery eyes $(57.69 \%)$. Other common ocular symptoms in group 1 included grittiness $(38.4 \%)$ and chemosis $(26.92 \%)$.

Table I. Distribution of ocular symptoms in the study groups

\begin{tabular}{lcc}
\hline Ocular Symptom & $\begin{array}{c}\text { Group 1 (SAC), } \\
\text { n (\%age) }\end{array}$ & $\begin{array}{c}\text { Group 2 (Controls), n } \\
\text { (\%age) }\end{array}$ \\
\hline Hyperemia & $21(80.76 \%)$ & $2(7.69 \%)$ \\
Pruritis & $18(69.23 \%))$ & $2(7.69 \%)$ \\
Watery Eyes & $15(57.69 \%)$ & $3(11.53 \%)$ \\
Grittiness & $10(38.4 \%)$ & $0(0 \%)$ \\
Chemosis & $7(26.92 \%)$ & $0(0 \%)$ \\
Visual blurring & $7(26.92 \%)$ & $0(0 \%)$ \\
Photophobia & $0(0 \%)$ & $0(0 \%)$ \\
Ophthalmalgia & $0(0 \%)$ & $0(0 \%)$ \\
\hline
\end{tabular}

Mean serum $\operatorname{IgE}$ levels were significantly higher in group 1 (2181.09 IU/ml +- 1062.33) as compared to group $2(54.83 \mathrm{IU} / \mathrm{ml}+$ - 26.67) with a p-value of 0.001 (Table II). Mean serum vitamin D levels were within the normal range in both the groups although levels were higher in group 1 as compared to group $2(38.96 \mathrm{ng} / \mathrm{ml}$ +- 11.37 vs. $29.47 \mathrm{ng} / \mathrm{ml}+$ - 11.73, $\mathrm{p}=0.005$ ) (Table II). Scores on the SPEED questionnaire were also significantly higher in group 1 as compared to group 2 $(19.42+-4.81$ vs. $2.19+-1.49, \mathrm{p}=0.001)$. There was no difference observed between the two groups in any $\mathrm{CBC}$ parameter (Table II).

\section{DISCUSSION}

SAC, which is an acute short-term ocular allergy, is the commonest form of allergic conjunctivitis. The present study primarily examined the role of serum vitamin $\mathrm{D}$ in SAC and studied its association with serum $\mathrm{IgE}$ through biochemical evaluation. The study also evaluated the
Table II. Group comparisons for mean serum IgE, vitamin D, SPEED scores and CBC parameters

\begin{tabular}{|c|c|c|c|}
\hline Parameters & $\begin{array}{l}\text { Group } 1 \text { (Mean +- } \\
\text { SD) }\end{array}$ & $\begin{array}{l}\text { Group } 2 \\
(\text { Mean + SD) }\end{array}$ & p-value \\
\hline $\begin{array}{l}\text { Serum IgE } \\
\text { (IU/mL) }\end{array}$ & $2181.09+-1062.33$ & $54.83+-26.67$ & $0.001^{*}$ \\
\hline $\begin{array}{l}\text { Serum } \\
\text { vitamin } D \\
(\mathrm{ng} / \mathrm{mL})\end{array}$ & $38.96+-11.37$ & $29.47+-11.73$ & $0.005^{*}$ \\
\hline SPEED score & $19.42+-4.81$ & $2.19+-1.49$ & $0.001 *$ \\
\hline $\begin{array}{l}\text { Hemoglobin } \\
(g / d L)\end{array}$ & $13.42+-1.90$ & $14.46+-2.02$ & 0.062 \\
\hline $\begin{array}{l}\text { RBC count } \\
\left(10^{12} / \mathrm{L}\right)\end{array}$ & $5.03+-0.67$ & $5.23+-0.64$ & 0.283 \\
\hline $\begin{array}{l}\text { Platelet count } \\
\left(10^{9} / \mathrm{L}\right)\end{array}$ & $202.76+-64.59$ & $221.03+-47.29$ & 0.250 \\
\hline $\begin{array}{l}\text { WBC count } \\
\left(10^{9} / \mathrm{L}\right)\end{array}$ & $7.42+-1.52$ & $7.39+-1.50$ & 0.716 \\
\hline $\begin{array}{l}\text { Neutrophils } \\
(\%)\end{array}$ & $54.65+-8.19$ & $55.26+-8.03$ & 0.786 \\
\hline $\begin{array}{l}\text { Lymphocytes } \\
(\%)\end{array}$ & $35.80+-7.03$ & $34.38+-7.36$ & 0.491 \\
\hline $\begin{array}{l}\text { Monocytes } \\
(\%)\end{array}$ & $6.65+-2.15$ & $6.30+-1.84$ & 0.537 \\
\hline $\begin{array}{l}\text { Eosinophils } \\
(\%)\end{array}$ & $3.19+-2.09$ & $4.84+-4.67$ & 0.106 \\
\hline
\end{tabular}

$*$ Difference significant at $\mathrm{p}<0.05$.

symptomatology of SAC using questionnaires and made comparison between patients with SAC and healthy individuals.

Allergic rhinitis was observed in nearly half of the SAC patients recruited in our study. These findings are consistent with those reported in existing literature which suggest association of allergic conjunctivitis with allergic rhinitis as well as other respiratory, dermal and food allergies. 3,4 The current data showed pink eye as the most common ocular symptom seen in more than four-fifths of the SAC patients, followed by ocular itching and watery eyes which were observed in more than two-thirds and more than half of the SAC patients respectively.

The scores on the SPEED questionnaire, which reflect severity and frequency of ocular symptoms, were markedly higher in SAC patients as compared to healthy individuals without SAC. Itching, redness and watering of eyes have previously been highlighted as common ocular symptoms of allergic conjunctivitis with considerable overlap between symptoms..$^{2,15}$

Our study shown serum IgE levels to be significantly higher in patients with SAC as compared to healthy people. These findings are concordant with numerous 
studies which have shown IgE-mediated hypersensitivity reactions to be at the core of the pathogenesis of SAC.4,16 A previous case-control study in a Turkish cohort showed greater mean total serum immunoglobulin $\mathrm{E}$ concentration in patients with type 1 allergic conjunctivitis as compared to healthy controls and contact lens wearers. ${ }^{17}$

On exposure of conjunctiva to allergen, T-helper type 2 (Th2) and B cells interact leading to release of interleukin-4 from Th2 cells which induces B cell activation, proliferation and differentiation into allergen -specific plasma cells that produce IgE. Binding of allergen-specific $\mathrm{IgE}$ to membrane receptors on conjunctival mast cells results in the priming of latter, thus allowing mast cells to degranulate on subsequent exposure to the same allergen and release contents including histamine, prostaglandins, leukotrienes and proteases that result in allergic manifestations. ${ }^{7}$

Our study also shown mean serum vitamin D levels was higher in patients with SAC as compared to healthy individuals. Data regarding the levels of vitamin $\mathrm{D}$ in patients suffering from SAC are almost non-existent. To-date, there is only a single published study by Dadaci et al. which investigated serum vitamin D levels in Turkish patients with SAC exclusively.

Our findings on serum vitamin D levels in SAC are contradictory to those reported by Dadaci et al which showed lower vitamin D levels in patients with SAC as compared to age and sex-matched healthy individuals. ${ }^{18}$ In their study, vitamin $D$ levels in both the SAC patients and healthy non-allergic controls were in the deficient range while our results demonstrated normal vitamin $\mathrm{D}$ levels in both groups. Identical electrochemiluminescence assay techniques were used for the laboratory estimation of vitamin D and both studies had comparable but small sample size.

The overall disparity in vitamin $\mathrm{D}$ levels between the Turkish and the present cohorts may be due to sampling issues (small number, convenience sampling) or possibly due to ethnic, racial, geographical or occupational variations. ${ }^{19-21}$ It is probable that higher concentrations of vitamin D may be associated with SAC in individuals with optimal vitamin D status whereas in individuals with vitamin D deficiency, lower levels may be associated with SAC. However, the available evidence is highly insufficient to derive any definitive conclusions about vitamin $D$ levels in SAC patients. In fact, there is still no clarity on the role of vitamin $\mathrm{D}$ in allergic disorders which have been relatively well studied 22 and some studies have even implicated high vitamin $\mathrm{D}$ levels in the development and progression of various allergies. ${ }^{12,23}$

\section{CONCLUSION}

The current study adds novel data to the negligible evidence-base regarding the involvement of vitamin $\mathrm{D}$ in SAC. In contrast to the previous findings, the present work suggests that higher serum vitamin D levels may be linked with SAC, thus highlighting the dire need for substantial further research to eliminate exiting inconsistencies and yield unambiguous inferences on the role of vitamin $\mathrm{D}$ in SAC.

\section{CONFLICT OF INTEREST}

The authors declare no conflict of interest for this work.

\section{ACKNOWLEDGEMENT}

The authors extend their appreciation to the Deanship of Scientific Research, University of Hafr Al-Batin for funding this work through the research group project No. G-103-2020.

\section{REFERENCES}

1. Miyazaki D, Fukagawa K, Okamoto S, et al. Epidemiological aspects of allergic conjunctivitis. Allergology Int 2020; 69(4):487-95.

2. Bielory L, Delgado L, Katelaris CH, et al. ICON: Diagnosis and management of allergic conjunctivitis. Ann Allergy Asthma Immunol 2020; 124(2):118-34.

3. Rathi VM, Murthy SI. Allergic conjunctivitis. Comm Eye Health J 2017; 29(99):S7-10.

4. Dupuis P, Prokopich CL, Hynes A, Kim H. A contemporary look at allergic conjunctivitis. Allergy Asthma Clin Immunol 2020; 16:5. 
5. Chen YH, Lin CL, Bau DT, Hung YC. Risk of allergic conjunctivitis in patients with type 1

diabetes mellitus: a population-based retrospective cohort study. BMJ Open 2017; 7 (6):e015795.

6. Alswailmi FK, Sikandar MZ, Shah SIA. Biological roles of vitamin $\mathrm{D}$ and immunoglobulin $\mathrm{E}$ : Implications in allergic disorders. Pak J Med Health Sci 2020; 14(3):495-8.

7. Chigbu DI, Minhas BK. Immunopathology of allergic conjunctivitis. Eur Med J 2018; 3(1):76-83.

8. Buyuker SM. Vitamin D deficiency and toxicity. Eurasian J Med Oncol 2019; 3(1):1-5.

9. Alswailmi FK, Shah SIA, Nawaz H. Immunomodulatory role of vitamin D: Clinical implications in infections and autoimmune disorders. Gomal J Med Sci 2020; 18(3):132-8

10. Mosaad YM, Mostafa M, Elwasify M, Youssef HM, Omar NM. Vitamin D and immune system. Vitam Miner 2017; 6(1):1000151.

11. Al-Swailmi FK, Shah SIA, Al-Mazaideh GM, Sikandar MZ. A cross-sectional analysis of serum vitamin $\mathrm{D}$ and immunoglobulin $\mathrm{E}$ in allergic disorders. Ann Clin Anal Med 2021; 10 (4328):20439.

12. Sikorska-Szaflik H, Sozanska B. The role of vitamin $\mathrm{D}$ in respiratory allergies prevention. Why the effect is so difficult to disentangle? Nutrients 2020; 12(6):1801.

13. Mathebula SD. Vitamin D in ocular and systemic health. African Vis Eye Health 2015; 74(1):35.

14. Pucker AD, Dougherty BE, Jones-Jordan LA, et al. Psychometric analysis of the SPEED questionnaire and CLDEQ-8. Invest Ophthalmol Vis Sci 2018; 59(8):3307-13.

15. Friedlaender MH. Ocular allergy. Curr Opin Allergy Clin Immunol 2011; 11(5):477-82.

16. Kocabeyoglu S, Bozkurt B, Bilen O, Irkec M, Orhan M. Serum allergen specific immunoglobulin E levels in patients with allergic conjunctivitis. Eur J Ophthalmol 2008; 18(5):6759.

17. Sahin OG, Taheri N. Serum immunoglobulin E levels in patients with allergic conjunctivitis and contact lens wearers. Asian J Ophthalmol 2011; 12:152-5.
18. Dadaci Z, Borazan M, Kiyici A, Acir NO. Plasma vitamin $\mathrm{D}$ and serum total immunoglobulin $\mathrm{E}$ levels in patients with seasonal allergic conjunctivitis. Acta Ophthalmol 2014; 92(6):4436.

19. Sowah D, Fan X, Dennett L, Hagtvedt R, Straube S. Vitamin D levels and deficiency with different occupations: a systematic review. BMC Public Health 2017; 17(1):519.

20. Yeum KJ, Song BC, Joo NS. Impact of geographic location on vitamin D status and bone mineral density. Int J Environ Res Public Health 2016; 13(2):184.

21. Correia A, Azevedo Mdo S, Gondim F, Bandeira F. Ethnic aspects of vitamin D deficiency. Arq Bras Endocrinol Metabol 2014; 58(5):540-4.

22. Alswailmi FK, Shah SIA, Sikandar MZ, Parrey MUR, Jelani S. Serum vitamin D, sun exposure and clinical attributes of local patients with respiratory allergies. Medical Science 2021; 25 (107):179-84.

23. Giustina AD, Landi M, Bellini F, et al. Vitamin $\mathrm{D}$, allergies and asthma: focus on pediatric patients. World Allergy Org J 2014; 7:27. 